\title{
Correlação da enzima DPP4 com a infecção por SARS-CoV-2
}

Correlation of DPP4 enzyme with SARS-CoV-2 infection

Correlación de la enzima DPP4 con la infección por SARS-CoV-2

Recebido: 03/10/2021 | Revisado: 10/10/2021 | Aceito: 14/10/2021 | Publicado: 17/10/2021

Lennara Pereira Mota ORCID: https://orcid.org/0000-0002-2629-6634 Centro Universitário Maurício de Nassau, Brasil E-mail: lennaramota@hotmail.com

Maria Vitalina Alves de Sousa ORCID: https://orcid.org/0000-0003-4448-2489 Centro Universitário INTA, Brasil E-mail: enf.vitalinaalves@gmail.com

Maria Jandeline do Nascimento Silva ORCID: https://orcid.org/0000-0003-3337-3332 Centro Universitário INTA, Brasil E-mail: jandelinesilvanascimento@gmail.com Amanda Eckhardt

ORCID: https://orcid.org/0000-0002-9733-9689 Centro Universitário INTA, Brasil E-mail: amanda_e2008@hotmail.com Domennique Miranda Vasconcelos ORCID: https://orcid.org/0000-0001-8119-6153 Centro Universitário INTA, Brasil E-mail: domenniquem@ gmail.com

Lyrlanda Maria Cavalcante de Almeida ORCID: https://orcid.org/0000-0003-0390-0090 Centro Universitário INTA, Brasil E-mail: 1yrlanda97@gmail.com Juliana Maria de Freitas ORCID: https://orcid.org/0000-0002-0651-3371 Centro Universitário INTA, Brasil E-mail: julianafhz@gmail.com

Alexandra Rodrigues Cardoso ORCID: https://orcid.org/0000-0002-7277-4668 Centro Universitário Maurício de Nassau, Brasil

E-mail: alexandrarodcar@gmail.com

Annyelli Victória Moura Oliveira ORCID: https://orcid.org/0000-0002-6898-9308 Universidade Estadual do Piauí, Brasil E-mail: annyellimoliveira@gmail.com

João Pedro Tavares De Oliveira ORCID: https://orcid.org/0000-0001-6887-1812

Centro Universitário Uninovafapi, Brasil E-mail: Jpto30@hotmail.com

Francilene Vieira Da Silva Freitas ORCID: https://orcid.org/0000-0003-3647-1587

Universidade Estadual do Maranhão, Brasil E-mail: francilenev@gmail.com

Ana Alinne Gomes Da Penha ORCID: https://orcid.org/0000-0001-9253-1199 Universidade Regional do Cariri, Brasil E-mail: anaalinne.nurse@gmail.com Eldson Rodrigues Borges ORCID: https://orcid.org/0000-0002-8848-0074

Centro Universitário Uninovafapi, Brasil E-mail: eldsonborges7@gmail.com

Joice Mara Ferreira Dos Santos ORCID: https://orcid.org/0000-0002-3231-750X Associação de Ensino Superior do Piauí, Brasil E-mail: joicinha2.2kinha@gmail.com Beatriz Caroline Leão Lima

ORCID: https://orcid.org/0000-0003-0382-3988 Universidade Estadual do Piaú, Brasil E-mail: beatrizcll@hotmail.com 


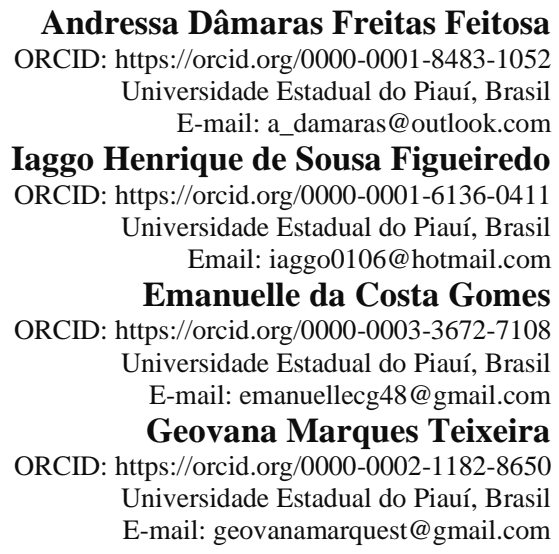

\begin{abstract}
Resumo
A COVID-19 se tornou uma questão de alto risco de preocupação global. O pico da glicoproteína (S) no envelope do vírion é clivado proteoliticamente nas subunidades S1 e S2, e o reconhecimento do receptor é mediado pelo domínio de ligação ao receptor (RBD) e fusão da membrana. Trata-se de uma revisão bibliográfica de caráter qualitativo que se baseia na produção científica a partir de estudos já publicados entre os anos de 2019 a 2021 que abordavam o objetivo principal deste estudo correlacionar a DPP4 na infecção por SARS-CoV-2. O tropismo dos coronavírus depende principalmente da capacidade do pico de entrada da glicoproteína (S) para se ligar aos receptores da superfície celular. Atualmente, é relatado que o SARS-CoV-2 pode usar a enzima de conversão da angiotensina-2 (ACE2), o mesmo receptor do SARS-CoV, para infectar humanos. No entanto, evidências recentes sugerem que o SARS-CoV-2 se liga ao DPP4 / CD26 após entrar nas células das vias aéreas. Parece que a interação entre a glicoproteína de pico SARS-CoV-2 e DPP4 / CD26 humana (também conhecida como dipeptidil peptidase-4 (DPP4) é um fator chave no sequestro e virulência. $\mathrm{Na}$ ausência de resultados de ensaios clínicos randomizados bem desenhados, os dados de eficácia ou segurança dos inibidores DPP4 no tratamento de COVID-19 devem ser interpretados com cautela e nenhuma conclusão clara pode ser feita. Os resultados desses estudos podem ajudar a revelar o impacto do uso de medicamentos que inibem a DPP4 e se eles podem ser eficazes no tratamento da infecção por COVID-19.
\end{abstract}

Palavras-chave: COVID-19; Enzima; Dipeptidil peptidase 4; Glicose.

\title{
Abstract
}

COVID-19 has become a high-risk issue of global concern. The glycoprotein (S) peak in the virion envelope is proteolytically cleaved into the S1 and S2 subunits, and receptor recognition is mediated by receptor binding domain (RBD) and membrane fusion. This is a literature review of a qualitative nature based on scientific production from studies published between 2019 and 2021 that addressed the main objective of this study to correlate DPP4 in SARSCoV-2 infection. Coronavirus tropism mainly depends on the ability of the glycoprotein (S) entry peak to bind to cell surface receptors. It is currently reported that SARS-CoV-2 can use angiotensin-2 converting enzyme (ACE2), the same receptor as SARS-CoV, to infect humans. However, recent evidence suggests that SARS-CoV-2 binds to DPP4/CD26 after entering airway cells. It appears that the interaction between the peak glycoprotein SARS-CoV-2 and human DPP4/CD26 (also known as dipeptidyl peptidase-4 (DPP4) is a key factor in sequestration and virulence. In the absence of results from well-designed randomized clinical trials, the efficacy or safety data of DPP4 inhibitors in the treatment of COVID-19 must be interpreted with caution and no clear conclusions can be drawn. The results of these studies may help reveal the impact of using drugs that inhibit DPP4 and whether they can be effective in the treatment of COVID-19 infection.

Keywords: COVID-19; Enzyme; Dipeptidyl peptidase 4; Glucose.

\section{Resumen}

COVID-19 se ha convertido en un problema de alto riesgo de preocupación mundial. El pico de glicoproteína (S) en la envoltura del virión se escinde proteolíticamente en las subunidades S1 y S2, y el reconocimiento del receptor está mediado por el dominio de unión al receptor (RBD) y la fusión de la membrana. Se trata de una revisión de la literatura de carácter cualitativo basada en la producción científica de estudios publicados entre 2019 y 2021 que abordaron el objetivo principal de este estudio de correlacionar DPP4 en la infección por SARS-CoV-2. El tropismo por coronavirus depende principalmente de la capacidad del pico de entrada de la glicoproteína (S) para unirse a los receptores de la superficie celular. Actualmente se informa que el SARS-CoV-2 puede usar la enzima convertidora de angiotensina-2 (ACE2), el mismo receptor que el SARS-CoV, para infectar a los seres humanos. Sin embargo, evidencia reciente sugiere que el SARS-CoV-2 se une a DPP4 / CD26 después de ingresar a las células de las vías respiratorias. Parece que la interacción entre el pico de glucoproteína SARS-CoV-2 y la DPP4 / CD26 humana (también conocida como dipeptidil peptidasa-4 (DPP4) es un factor clave en el secuestro y la virulencia. En ausencia de resultados de estudios clínicos 
aleatorizados bien diseñados ensayos, los datos de eficacia o seguridad de los inhibidores de la DPP4 en el tratamiento de COVID-19 deben interpretarse con precaución y no se pueden sacar conclusiones claras. Los resultados de estos estudios pueden ayudar a revelar el impacto del uso de fármacos que inhiben la DPP4 y si pueden ser eficaz en el tratamiento de la infección por COVID-19.

Palabras clave: COVID-19; Enzima; Dipeptidil peptidasa 4; Glucosa.

\section{Introdução}

A pandemia causada pela infecção pelo coronavírus 2019 (COVID-19) é causada por um novo $\beta$-coronavírus (SARSCoV-2), que leva a uma síndrome respiratória aguda grave, semelhante à SARS-CoV e à Síndrome Respiratória do Oriente Médio (MERS-CoV), que provoca síndrome da dificuldade respiratória e casos fatais. Entre pacientes idosos, obesos, com comorbidades como diabetes, hipertensão, doença cardiovascular e doença pulmonar crônica, a gravidade da doença COVID-19 é mais fatal (Bassendine et al., 2020).

A COVID-19 se tornou uma questão de alto risco de preocupação global. O patógeno SARS-CoV-2 demonstrou ser um membro do beta coronavírus intimamente relacionado ao SARS-CoV e à cepa RaTG13 de origem de morcego. O pico da glicoproteína (S) no envelope do vírion é clivado proteoliticamente nas subunidades S1 e S2, e o reconhecimento do receptor é mediado pelo domínio de ligação ao receptor (RBD) e fusão da membrana. Os receptores são os principais determinantes do tropismo do hospedeiro e da patogenicidade viral (Li et al., 2020).

Tanto o SARS-CoV quanto o SARS-CoV-2 usam ACE2 como o principal receptor para o vírus entrar na célula hospedeira. No entanto, a combinação de métodos de bioinformática que preveem interações de proteína-vírus humana, docking seletivo baseado em modelo computacional e docking de proteína baseada em estrutura cristalina indicam que DPP-4 é um candidato alvo de ligação para o domínio de ligação do receptor S1 viral. Além disso, os resíduos de ligação chave de DPP-4 são os mesmos que aqueles ligados à proteína de pico MERS-CoV. Como o DPP-4 é expresso de forma ubíqua em várias células e tecidos fora do pulmão e do trato respiratório, ele pode participar diretamente nos danos mediados por SARS-CoV-2 a esses tecidos (Pinheiro et al., 2021).

Um estudo recente relatou claramente a correlação entre DPP4 e ACE2, indicando que ambas as proteínas de membrana estão envolvidas na patogênese da entrada do vírus. A co-expressão de ACE2 e DPP4 / CD26 como pico de receptores de glicoproteína pode assumir que diferentes coronavírus humanos (CoV) têm como alvo tipos de células semelhantes em diferentes tecidos humanos e explicar as características clínicas semelhantes em pacientes com diferentes infecções por CoV. Em outro caso, foi demonstrado que o DPP4 atua no co-receptor CoV, indicando que o potencial mecanismo de entrada do SARS-CoV-2 é semelhante (Solerte et al., 2020).

A DPP4 é o receptor MERS-CoV e tem vantagens na mediação de infecções por coronavírus. Foi demonstrado que DPP4 não pode mediar independentemente SARS-CoV-2 em células não licenciadas, como HeLa e BHK2. No entanto, seu papel na fixação e / ou entrada nas células permissivas durante a infecção por SARS-CoV-2 ainda é desconhecido. DPP4 pode ser usado como um alvo de ligação candidato para RBD SARS-CoV-2-S (Li et al., 2020).

A enzima de conversão da angiotensina-2 (ACE-2) é um componente do sistema renina-angiotensina-aldosterona (RAAS) e é o receptor de superfície celular para SARS-CoV-2. Um estudo recente provou que o coronavírus SARS-CoV-2 também usa a dipeptidil peptidase-4 (DPP4, também conhecida como proteína do complexo adenosina desaminase 2, CD26) como co-receptor ao entrar nas células. Além disso, a DPP4 também está envolvida na regulação da resposta imune (Khin et al., 2020).

A ligação do vírus é importante para a adesão celular, entrada na célula hospedeira e desenvolvimento de virulência. Portanto, a inibição de DPP4 pode impedir que o vírus entre na célula hospedeira. No entanto, até o momento, não há dados que comprovem claramente que DPP4 também seja o receptor do SARS-CoV-2. DPP4 foi identificado como um candidato potencial 
por estudos estruturais e ainda não foi confirmado em células humanas. Além disso, foi levantada a hipótese de que a inibição de DPP4 pode antagonizar a virulência de SARS-CoV-2, reduzindo as tempestades de citocinas e a inflamação pulmonar (Bonora,; Avogaro; Fadini, 2021).

Vários estudos também mostraram que o SARS-CoV-2 pode usar um co-receptor ao entrar nas células, o receptor da dipeptidil peptidase 4 (DPP4) (também usado pelo MERS-Co-V). Em particular, embora o nível de expressão de ACE-2 seja muito baixo, ele ainda pode infectar linfócitos T, o que significa um receptor alternativo para a entrada do vírus. A DPP-4, também conhecida como proteína do complexo adenosina desaminase 2 ou CD26, está envolvida em vários processos fisiológicos e doenças do sistema imunológico. DPP-4 é expresso de forma ubíqua em vários tecidos, incluindo pulmão, rim, intestino delgado e coração. Esses tecidos também são danificados principalmente em pacientes infectados com COVID-19 (Khin et al., 2020).

A DPP4 controla a resposta imune agindo como uma molécula coestimuladora nas células T e regula a homeostase da glicose pela degradação do hormônio incretina. Evidências recentes levantam a questão de saber se a regulação ou inibição de DPP4 pode prevenir a infecção e / ou progressão de COVID-19 (Strollo; Pozzilli, 2020).

O trabalho tem por objetivo expor através da análise de artigos científicos a correlação entre a enzima dipeptidil peptidase 4 na infecção por SARS-CoV-2.

\section{Métodos}

Trata-se de uma revisão bibliográfica de caráter qualitativo que se baseia na produção científica a partir de estudos já publicados. A busca pelos textos foi realizada a partir das seguintes palavras-chaves indexadas no DECS (Descritores em Ciências da Saúde): “Covid-19”, “Enzima”, "Dipeptidil peptidase 4” e Glicose na plataforma Scientific Electronic Library Online (SCIELO) e Biblioteca Virtual em Saúde (BVS).

Os critérios de inclusão foram pesquisas científicas publicadas de 2019 a 2021, publicados no idioma português, inglês e espanhol, que atendiam ao problema da pesquisa: Qual a correlação da enzima DPP4 com infecção por SARS-CoV-2? Os critérios de exclusão foram trabalhos científicos com apenas resumos disponíveis, publicações duplicadas, artigos de relato de experiência, reflexivo, editoriais, comentários e cartas ao editor.

A partir do problema de pesquisa foram selecionados artigos publicados em periódicos nacionais e internacionais escolhidos a partir de levantamento realizado por meios dos descritores na biblioteca virtual Scientific Electronic Library Online, Biblioteca Virtual em Saúde (BVS) e dissertações e teses.

Os artigos foram selecionados para leitura e foram incluídos na análise quantitativa artigos que se enquadravam no tema proposto do trabalho.

\section{Resultados e Discussão}

A Figura 1 ilustra os resultados deste trabalho que foram obtidos através da análise quantitativa de publicações sobre a correlação da DPP4 com a infecção por SARS-CoV-2 nas bases de dados Scientific Electronic Library Online e Biblioteca Virtual em Saúde (BVS). 
Figura 1: Fluxograma que apresenta o processo de seleção das publicações sobre a DPP4 na infecção por SARS-CoV-2, Teresina, Brasil, 2021.

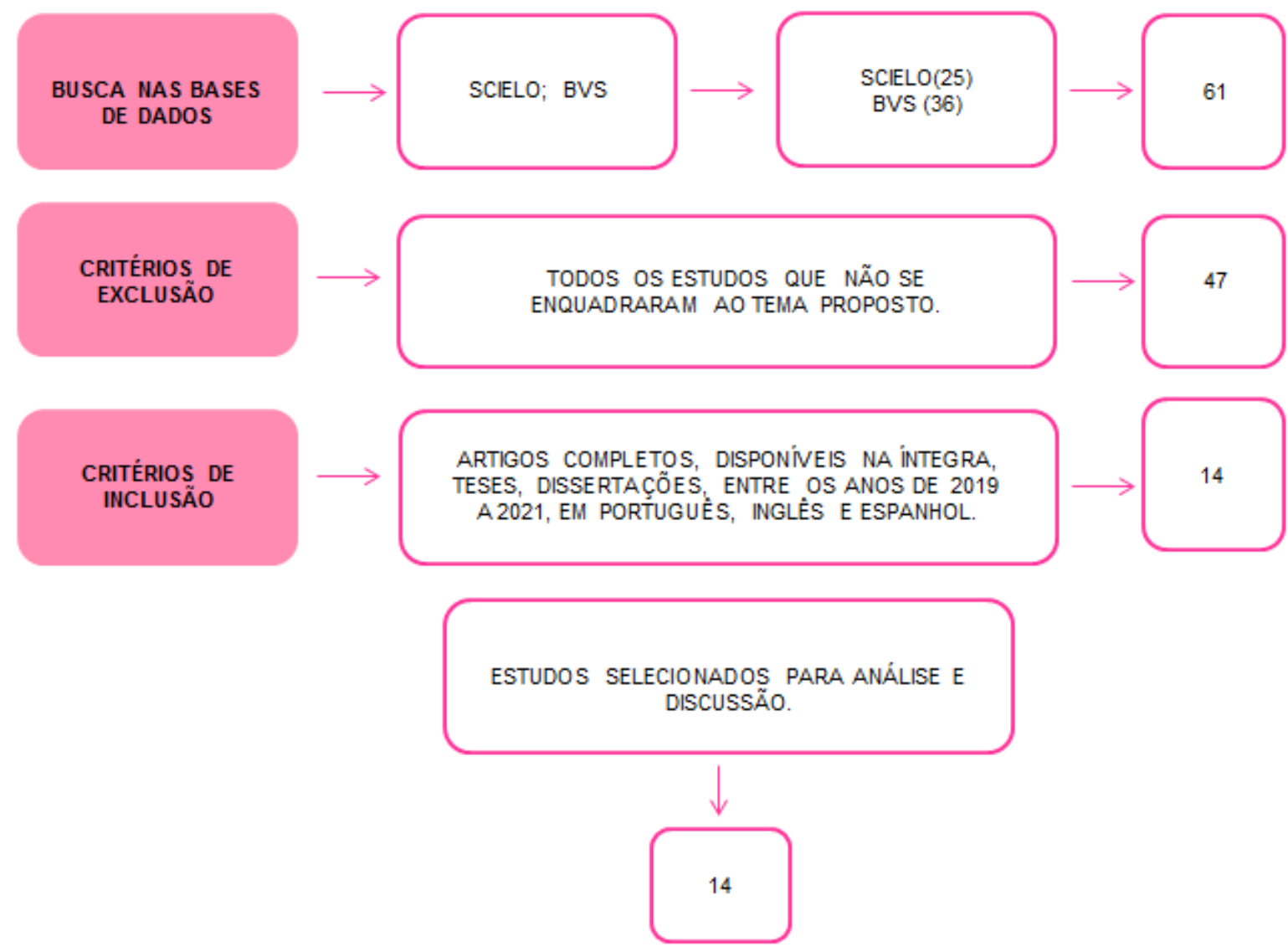

Fonte: Mota et al. (2021).

Os resultados deste trabalho foram obtidos através da análise quantitativa de publicações sobre a correlação da enzima DPP4 com a infecção por SARS-CoV-2 encontrados nas bases de dados Scientific Electronic Library Online e Biblioteca Virtual em Saúde obtendo 25 artigos na Scielo e 36 artigos na BVS. Foram excluídos 19 artigos da Scielo e 28 da BVS por não se enquadrarem no tema proposto. Foram incluídos na análise e nos resultados 06 artigos da Scielo e 08 artigos da BVS entre os anos de 2019 a 2021.

De acordo com os artigos científicos encontrados nota-se que a COVID-19 se tornou uma pandemia global no início de 2020. Não afeta apenas principalmente as vias respiratórias superiores e inferiores, mas também muitos órgãos, incluindo os rins, o coração e o cérebro. A taxa de mortalidade de pacientes com COVID-19 é alta entre homens e idosos com doenças relacionadas à idade, como hipertensão e diabetes (Khin et al., 2020).

O coronavírus desenvolveu um padrão complexo de reconhecimento de receptor. Os picos de coronavírus relacionados podem reconhecer receptores diferentes, enquanto os picos de coronavírus distantes podem usar o mesmo receptor de entrada. Por exemplo, o SARS-CoV usa a enzima conversora de angiotensina 2 (ACE2) como seu receptor primário, enquanto o MERS-CoV envolve a dipeptidil peptidase 4 transmembrana (DPP4, também conhecido como (CD26) como seu principal receptor (Li et al., 2020).

O tropismo dos coronavírus depende principalmente da capacidade do pico de entrada da glicoproteína (S) para se ligar aos receptores da superfície celular. Atualmente, é relatado que o SARS-CoV-2 pode usar a enzima de conversão da angiotensina-2 (ACE2), o mesmo receptor do SARS-CoV, para infectar humanos. No entanto, evidências recentes sugerem que o 
SARS-CoV-2 se liga ao DPP4 / CD26 após entrar nas células das vias aéreas. Parece que a interação entre a glicoproteína de pico SARS-CoV-2 e DPP4 / CD26 humana (também conhecida como dipeptidil peptidase-4 (DPP4) é um fator chave no sequestro e virulência (Solerte et al., 2020).

As características clínicas do COVID-19 refletem a capacidade do SARS-Cov-2 de infectar diferentes tecidos e suas células constituintes, que por sua vez ecoa a expressão dos receptores de fixação / ligação do vírus. Embora a ACE2 seja expressa em células do pulmão e do intestino delgado, um estudo recente mostrou que a expressão em células alveolares do tipo 2 é bastante baixa em comparação com outras células que expressam ACE2, o que revela a possibilidade do SARS-CoV-2 utilizar co-receptores. Estudos mostram que a ACE2 é altamente expressa nos rins e intestinos (esôfago, estômago, íleo, cólon e reto) e está relacionada à expressão de outras peptidases utilizadas pelos coronavírus como receptores de entrada. Verificou-se que DPP4 é o primeiro gene a se agrupar com ACE2, e como a modelagem mostra que há uma interação próxima entre SARS-CoV-2, S1 e DPP4, a distribuição de DPP4 no tecido é considerada relevante (Bassendine et al., 2020).

A Figura 2 demonstra os principais locais em que ocorre expressão de DPP4.

Figura 2: A Figura 2 mostra a expressão da dipeptidil peptidase 4 (DPP4) no epitélio e endotélio. Em humanos, o DPP4 é fortemente expresso na superfície apical do epitélio polarizado, incluindo pulmão, fígado (hepatócitos e células do ducto biliar), pâncreas (células acinares), intestino e túbulos renais. A DPP4 também está presente na superfície interna das células endoteliais de capilares.

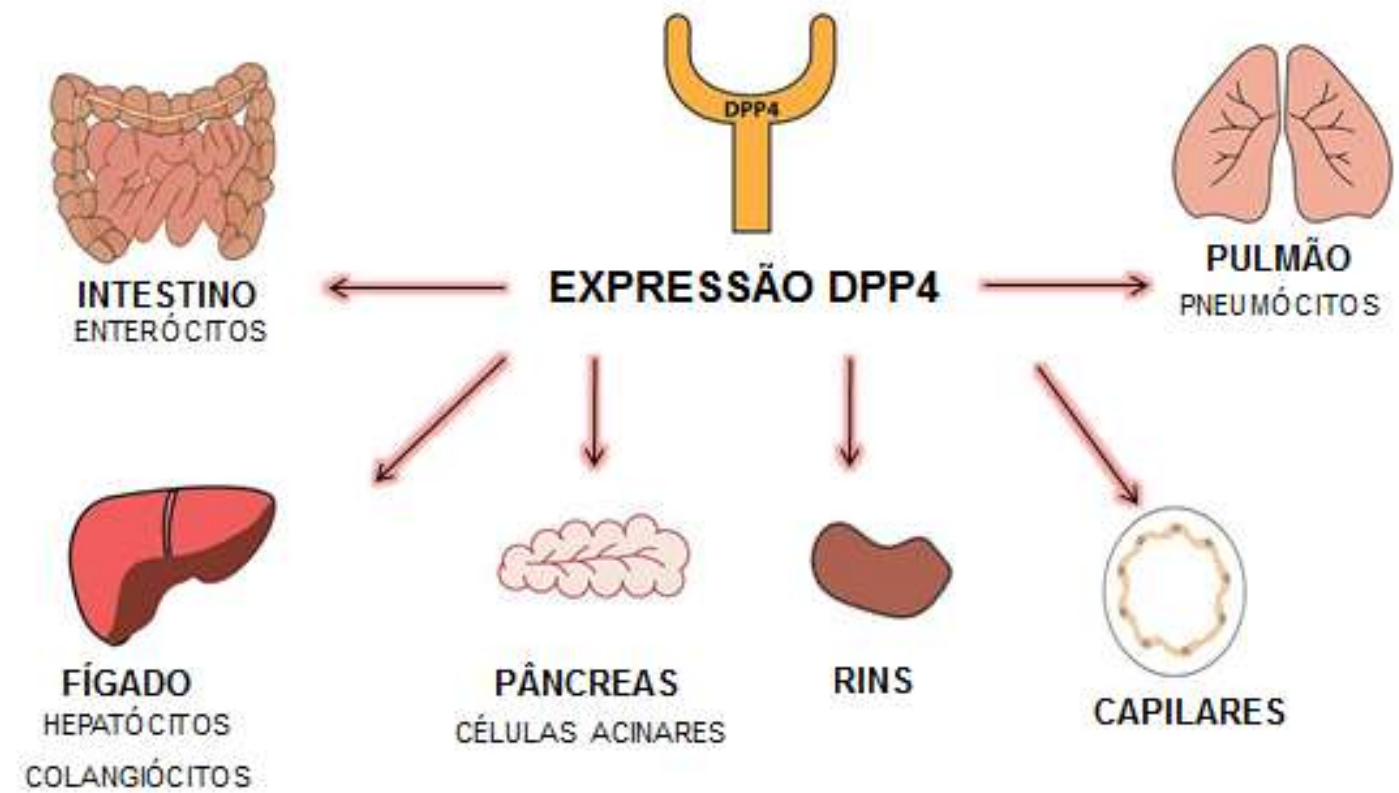

Fonte: Adaptado de Bassendine et al. (2020).

Além do epitélio e endotélio, a DPP4 é amplamente expressa em células imunes ativadas, incluindo células T CD4 (+) e CD8 (+), células B, células assassinas naturais, células dendríticas e macrófagos. Pode regular a produção de citocinas, quimiocinas e hormônios peptídicos, por isso participa de várias doenças imunológicas ou inflamatórias. No entanto, para todos, devemos entender a interação entre DPP4 e o receptor principal ACE2, e como o DPP4 ajuda o SARS-CoV-2 a entrar na célula hospedeira (Li et al., 2020).

O SARS-CoV-2 usa a enzima de conversão da angiotensina-2 para invadir células humanas. No entanto, evidências recentes sugerem que a dipeptidil peptidase 4 (DPP-4) pode atuar como um co-receptor quando o SARS-CoV-2 entra nas células consideradas hospedeiras. A regulação positiva da DPP-4 está associada à idade avançada, diabetes, síndromes respiratórias ou 
problemas cardiovasculares, as principais comorbidades responsáveis por agravar a COVID-19 (Noh et al., 2021).

O curso de qualquer infecção viral aguda é determinado por fatores do hospedeiro, incluindo resposta imune e estratégias virais para evitar essa resposta a fim de estabelecer a replicação primária e rápida. Em SARS e MERS, a carga viral de pacientes graves é maior do que a de pacientes leves, e o tempo de eliminação do vírus nas secreções respiratórias é maior. Isso significa que, entre aqueles com comorbidades, o equilíbrio é tendencioso para vírus. A interação inicial entre o vírus e a célula hospedeira é necessária para a produção da infecção viral e o início do ciclo de vida do vírus. Portanto, os fatores do hospedeiro necessários para as interações entre SARS-CoV-2 e hospedeiro no processo de fixação, ligação e entrada são importantes não apenas no desenvolvimento da vacina, mas também na patogênese e no tratamento da doença (Bassendine et al., 2020).

A inflamação adequada é uma parte importante de uma resposta imune eficaz que elimina os patógenos e, em última análise, leva ao reparo do tecido e à restauração da homeostase. No entanto, o SARS-CoV-2 pode induzir uma resposta excessiva e prolongada de citocinas em síndrome do desconforto respiratório agudo (SDRA) ou síndrome de disfunção de múltiplos órgãos (MODS) ou mesmo em casos de óbito. Embora seja necessário esclarecer que DPP-4 está diretamente envolvida na infecção por SARS-CoV-2, há evidências de que os inibidores DPP-4 podem ter benefícios potenciais para pacientes com COVID-19 (Du et al., 2020; Marinho et al., 2021).

No passado, foi demonstrado que as proteases ligadas à membrana, como a dipeptidil peptidase (DPP) -4 e a enzima de conversão da angiotensina (ACE) 2, atuam como parceiros de ligação para o coronavírus entrar nas células imunes do hospedeiro. Uma publicação recente mostrou que o domínio S1 da glicoproteína de pico Sars-CoV-2 pode interagir com a DPP-4 humana ligada à membrana (Schlicht et al., 2020).

A dipeptidil peptidase 4 (DPP4), também conhecida como CD26, é uma glicoproteína transmembrana que está quase universalmente presente na superfície de muitas células, incluindo células epiteliais e endoteliais de muitos tecidos e em células do sistema imunológico. A DPP4 desempenha um papel importante na regulação do sistema imunológico, promovendo a ativação e proliferação de células $\mathrm{T}$, regulando a função de outras células imunológicas e estimulando a produção de citocinas próinflamatórias. A DPP4 também está presente na circulação de forma solúvel, onde mantém sua atividade enzimática. A DPP4 degrada o peptídeo-1 semelhante ao glucagon (GLP-1) fisiologicamente e desempenha um papel no metabolismo da glicose. Ela tem muitos outros substratos, incluindo citocinas, quimiocinas e fatores de crescimento. Também atua como um ligante para proteínas de ligação e fatores extracelulares. Há evidências de que a DPP4 humana é o receptor funcional da glicoproteína de pico MERS-CoV (MERS-CoV), que está filogenicamente relacionado ao SARS-CoV-2 (Bonora; Avogaro; Fadini, 2021; Trzaskalski et al., 2020).

DPP4 é uma serina protease amplamente distribuída em tecidos humanos e funciona como uma proteína multifuncional. Além do trato respiratório inferior, rins, fígado, intestino delgado e próstata, DPP4 também está presente na placenta, fibroblastos pulmonares e lesões na pele, músculos e sistema nervoso central (Li et al., 2020; Iacobellis, 2020).

A dipeptidil peptidase 4 (DPP4) foi recentemente proposta como um alvo potencial para COVID-19. DPP4 é uma exopeptidase de serina, que é expressa de forma ubíqua em muitos tecidos, incluindo, pulmão, rim, fígado, intestino e células do sistema imunológico. A DPP4 pode clivar uma variedade de substratos, incluindo fatores de crescimento, quimiocinas, neuropeptídeos e peptídeos vasoativos. Portanto, participa de diversos processos fisiológicos (Strollo; Pozzilli, 2020; Vieira et al., 2020).

A inibição de DPP-4 pode ter o potencial de neutralizar o isolamento e a virulência de SARS-CoV-2 mediado por DPP-4 e melhorar o resultado clínico de COVID-19 interferindo na interação entre SARS-CoV-2 e a célula hospedeira de destino. No entanto, os principais mecanismos independentes de glicose que podem levar aos efeitos benéficos de DPP-4i em COVID-19 incluem as propriedades imunomoduladoras, antiinflamatórias e antifibróticas dessas drogas, que podem ser uma ferramenta de 
tratamento eficaz em casos mais graves ou para prevenir a progressão (Pinheiro et al., 2021; Yang et al., 2021).

Embora seja necessário comprovar se DPP4 está envolvida na infecção por SARS-CoV-2, há evidências de que o DPP4i pode regular a inflamação e exercer atividade antifibrótica. Essas propriedades podem ter usos potenciais na prevenção da progressão para um estado altamente inflamatório associado a COVID-19 grave. A DPP4i inibe a proliferação de células T e a produção de citocinas pró-inflamatórias (Strollo; Pozzilli, 2020; Kow; Hasan, 2020).

\section{Conclusão}

O SARS-CoV-2 é o vírus que está presente na COVID-19. Ele utiliza a enzima de conversão da angiotensina-2 para invadir células humanas e faze-las de hospedeiro. No entanto, evidências recentes demonstram que a DPP-4 pode atuar como um co-receptor quando o SARS-CoV-2 entra nas células-alvo. Curiosamente, a regulação da DPP-4 está associada à pacientes idosos, doenças respiratórias ou cardiovasculares e diabetes, todas as comorbidades que agravam a COVID-19.

É notável que a infecção por SARS-CoV- 2 é uma ameaça para a humanidade, sendo uma doença que possui alta taxa de mortalidade. Sabe-se que a enzima ACE2 tem um papel importante durante a infecção da célula hospedeira e diversos estudos evidenciaram a possibilidade da DPP4 ser co-receptor neste processo, mas é necessário que sejam realizados estudos clínicos para que essa possibilidade seja confirmada.

$\mathrm{Na}$ ausência de resultados de ensaios clínicos randomizados bem desenhados, os dados de eficácia ou segurança dos inibidores DPP4 no tratamento de COVID-19 devem ser interpretados com cautela e nenhuma conclusão clara pode ser feita. Os resultados desses estudos podem ajudar a revelar o impacto do uso de medicamentos que inibem a DPP4 e se eles podem ser eficazes no tratamento da infecção por COVID-19.

É necessário o desenvolvimento de estudos clínicos mais detalhados para que seja possível mensurar o impacto que a enzima DPP4 tem na infecção pelo vírus SARS-CoV-2 e se os seus inibidores possuem efeitos terapêuticos na COVID-19.

\section{Referências}

Bassendine, M. F, Bridge, S. H, McCaughan, G. W \& Gorrell, M. D (2020). COVID - 19 e comorbidades: Um papel da dipeptidil peptidase 4 (DPP4) na gravidade da doença? Journal of diabetes, 12 (9), 649-658.

Bonora, B. M, Avogaro, A., \& Fadini, G. P (2021). Desembaraçando evidências conflitantes sobre os inibidores DPP-4 e os resultados do COVID-19: revisão narrativa e meta-análise. Journal of Endocrinological Investigation , 1-8.

Du, H., Wang, D. W \& Chen, C. (2020). Os efeitos potenciais dos inibidores DPP-4 no sistema cardiovascular em pacientes COVID-19. Journal of Cellular and Molecular Medicine, 24 (18), 10274-10278.

Iacobellis, G. (2020). COVID-19 e diabetes: a inibição de DPP4 pode desempenhar um papel? Pesquisa e prática clínica sobre diabetes, 162.

Khin, P. P., Cha, S. H., Jun, H. S., \& Lee, J. H. (2020). A potential therapeutic combination for treatment of COVID-19: synergistic effect of DPP4 and RAAS suppression. Medical hypotheses, 144, 110-186.

Kow, C. S \& Hasan, S. S (2020). Uma meta-análise sobre o uso de inibidores da DPP-4 antes da admissão e o risco de um curso grave ou fatal da doença em pacientes com COVID-19. Therapie.

Li, Y., Zhang, Z., Yang, L., Lian, X., Xie, Y., Li, S., \& Lu, J. (2020). The MERS-CoV receptor DPP4 as a candidate binding target of the SARS-CoV-2 spike. Iscience, 23(6), 101-160.

Marinho, F. P., de Loyola, I. S., Monteiro, I. D. O. F., Castro, T. M., de Souza Carvalho, M. D. G., Garcia, J. A. D., \& Santos, G. B. (2021). Inter-relação entre COVID-19 e diabetes mellitus: uma revisão sistemática. Research, Society and Development, 10(2), e4810212191-e4810212191.

Noh, Y., Oh, I. S, Jeong, H. E, Filion, K. B, Yu, O. H. Y, \& Shin, J. Y (2021). Associação entre inibidores DPP-4 e desfechos relacionados ao COVID-19 entre pacientes com diabetes tipo 2. Cuidados com a diabete, 44 (4), e64-e66.

Pinheiro, M. M, Fabbri, A., \& Infante, M. (2021). Modulação de tempestade de citocinas em COVID-19: um papel proposto para a terapia combinada de vitamina D e inibidor de DPP-4 (VIDPP-4i). Immunotherapy, 13 (9), 753-765.

Schlicht, K., Rohmann, N., Geisler, C., Hollstein, T., Knappe, C., Hartmann, K., \& Laudes., M. (2020). Os níveis circulantes de dipeptidilpeptidase-4 solúvel são reduzidos em seres humanos hospitalizados por infecções graves por COVID-19. International Journal of Obesity , 44 (11), $2335-2338$. 
Research, Society and Development, v. 10, n. 13, e415101321361, 2021

(CC BY 4.0) | ISSN 2525-3409 | DOI: http://dx.doi.org/10.33448/rsd-v10i13.21361

Solerte, S. B, Di Sabatino, A., Galli, M., \& Fiorina, P. (2020). Inibição da dipeptidil peptidase-4 (DPP4) em COVID-19. Acta diabetologica, $57,779-783$.

Strollo, R. \& Pozzilli, P. (2020). Inibição de DPP4: prevenção da infecção por SARS - CoV - 2 e / ou progressão de COVID - 19? Pesquisa e revisões sobre diabetes / metabolismo, 36 (8), e3330.

Trzaskalski, N. A, Fadzeyeva, E., \& Mulvihill, E. \& (2020). Dipeptidil peptidase-4 na interface entre a inflamação e o metabolismo. Clinical Medicine Insights: Endocrinology and Diabetes, $13,1179551420912972$.

Vieira, G. D. V., de Lucas Xavier, J. O., de Oliveira Freitas, J. C., \& de Sousa, O. V. (2020). Agonistas do receptor de GLP-1 e inibidores da serino-protease dipeptidil-peptidase-4 no tratamento de diabetes tipo 2-Uma revisão. Brazilian Journal of Health Review, 3(4), 7654-7675.

Yang, Y., Cai, Z., \& Zhang, J. (2021). Os inibidores DPP-4 podem melhorar a mortalidade da doença coronavírus 2019: Uma meta-análise. PloS one, 16 (5), e0251916. 